Sean J. Colloby, PhD Ian G. McKeith, MD David J. Burn, MD David J. Wyper, PhD John T. O'Brien, DM* John-Paul Taylor, $\mathrm{PhD}^{*}$

Correspondence to Dr. Colloby: sean.colloby@ncl.ac.uk

Supplemental data at Neurology.org

\section{Cholinergic and perfusion brain networks in Parkinson disease dementia} OPEN

\section{ABSTRACT}

Objective: To investigate muscarinic M1/M4 cholinergic networks in Parkinson disease dementia (PDD) and their association with changes in Mini-Mental State Examination (MMSE) after 12 weeks of treatment with donepezil.

Methods: Forty-nine participants (25 PDD and 24 elderly controls) underwent ${ }^{123}$-QNB and ${ }^{99 m}$ Tc-exametazime SPECT scanning. We implemented voxel principal components (PC) analysis, producing a series of PC images of patterns of interrelated voxels across individuals. Linear regression analyses derived specific M1/M4 and perfusion spatial covariance patterns (SCPs).

Results: We found an M1/M4 SCP of relative decreased binding in basal forebrain, temporal, striatum, insula, and anterior cingulate $\left(F_{1,47}=31.9, p<0.001\right)$ in cholinesterase inhibitor-naive patients with PDD, implicating limbic-paralimbic and salience cholinergic networks. The corresponding regional cerebral blood flow SCP showed relative decreased uptake in temporoparietal and prefrontal areas $\left(F_{1,47}=177.5, p<0.001\right)$ and nodes of the frontoparietal and default mode networks (DMN). The M1/M4 pattern that correlated with an improvement in MMSE $(r=0.58$, $p=0.005$ ) revealed relatively preserved/increased pre/medial/orbitofrontal, parietal, and posterior cingulate areas coinciding with the DMN and frontoparietal networks.

Conclusion: Dysfunctional limbic-paralimbic and salience cholinergic networks were associated with PDD. Established cholinergic maintenance of the DMN and frontoparietal networks may be prerequisite for cognitive remediation following cholinergic treatment in this condition. Neurology ${ }^{\circledR}$ 2016;87:178-185

\section{GLOSSARY}

AIC = Akaike information criterion; CAMCOG = Cambridge Cognitive Examination; CAMCOGexec $=$ Cambridge Cognitive Examination executive function subscale; $\mathbf{C A M C O G}_{\text {memory }}=$ Cambridge Cognitive Examination memory subscale; ChEI = cholinesterase inhibitor; DLB = dementia with Lewy bodies; DMN = default mode network; MMSE = Mini-Mental State Examination; NBM = nuclear basalis of Meynert; NPI = Neuropsychiatric Inventory; PC = principal component; PD = Parkinson disease; $\mathbf{P D D}=$ Parkinson disease dementia; $\mathbf{r C B F}=$ regional cerebral blood flow; $\mathbf{S C P}=$ spatial covariance pattern; $\mathbf{S N}=$ salience network; SSF = subject scaling factor.

In Parkinson disease (PD), development of dementia (PDD) occurs in up to $80 \%$ of people $15-20$ years after PD diagnosis, ${ }^{1}$ with $50 \%$ developing cognitive impairment within 6 years. ${ }^{2}$ In PDD, cholinergic dysfunction is strongly implicated in cognitive deficits, fluctuating cognition, and visual hallucinations. ${ }^{3}$ Reductions in choline acetyltransferase are marked in PDD compared to Alzheimer disease and PD, ${ }^{4}$ while clinically, cholinesterase inhibitors (ChEIs) can ameliorate cognition and visual hallucinations. However, response is variable with some efficacy. ${ }^{5}$

Since the brain is a networked entity, pathologic change in one area may influence other topographically distant regions. Indeed, distributed network dysfunction is now considered a key contributor to symptoms that manifest in neurodegenerative dementias. ${ }^{6}$ In PDD, theoretical models of dysfunctional neural networks have been proposed. In particular, several cholinergic networks arising from the nuclear basalis of Meynert (NBM) projecting to

\footnotetext{
*These authors contributed equally to this work as joint senior authors.

From the Institute of Neuroscience (S.J.C., I.G.M., D.J.B., J.-P.T.), Newcastle University, Campus for Ageing and Vitality, Newcastle upon Tyne; SINAPSE (D.J.W.), Institute of Neuroscience and Psychology, University of Glasgow; and Department of Psychiatry (J.T.O.), University of Cambridge, UK. Go to Neurology.org for full disclosures. Funding information and disclosures deemed relevant by the authors, if any, are provided at the end of the article. The Article Processing Charge was paid by the National Institute of Health Research (United Kingdom) Biomedical Research Unit (Newcastle upon Tyne). This is an open access article distributed under the terms of the Creative Commons Attribution-NonCommercial-NoDerivatives License 4.0 (CC BY-NC-ND), which permits downloading and sharing the work provided it is properly cited. The work cannot be changed in any way or used commercially.
} 
specific brain regions are thought to affect major cognitive domains, e.g., attention (NBM $\rightarrow$ neocortex), visuoperceptual (NBM $\rightarrow$ parietooccipital, parahippocampal-fusiform), and memory (NBM $\rightarrow$ medial temporal). ${ }^{7}$ One way to examine functional brain connectivity is by spatial covariance analysis.

We applied spatial covariance to $(\mathrm{R}, \mathrm{R}){ }^{123} \mathrm{I}$ QNB SPECT data, ${ }^{8}$ acquired in ChEI-naive patients with $\mathrm{PDD}$, to investigate diseaseassociated M1/M4 cholinergic networks. Also, as cholinergic network dysfunction is implicated in cognitive impairment and amelioration of cholinergic function is an important aspect of treatment, we derived an M1/M4 covariance pattern that correlated with a change in MiniMental State Examination (MMSE) score, after 12 weeks of treatment with the ChEI (donepezil), to probe the clinical significance of these networks.

METHODS Standard protocol approvals, registrations, and patient consents. Study approval was from the UK Department of Health's Administration of Radioactive Substances Advisory Committee and Newcastle, North Tyneside, and Northumberland research ethics committees. All participants or nearest relatives gave written informed consent for the study including treatment.

Participants. The study comprised 49 individuals (25 PDD and 24 similarly aged controls). Patients were recruited from outpatient movement disorder clinics in Newcastle-upon-Tyne and Gateshead, while healthy controls were from patient spouses and friends in this and other studies. Participants had physical, neurologic, and neuropsychiatric assessments, including mental state, history, physical examination, and, for patients, blood screen with $\mathrm{B}_{12}$ and folate levels. The study battery administered included the MMSE, ${ }^{9}$ Neuropsychiatric Inventory (NPI) ${ }^{10}$ and Cambridge Cognitive Examination $(\mathrm{CAMCOG})^{11}$ with memory and executive function subscales $\left(\mathrm{CAMCOG}_{\text {memory }}, \mathrm{CAMCOG}_{\text {exec }}\right)$.

Diagnosis was carried out consensually between 2 clinicians using the diagnostic criteria for PDD. ${ }^{12}$ Patients with PDD were on levodopa and carbidopa or benserazide combination therapy and were naive to ChEI treatment at the time of QNB imaging. Participants on any of the following medications were excluded from the study: antipsychotics, cholinergics, anticholinergics, and antidepressant medications. Clinicopathologic diagnosis was established for 11 cases (2 controls, 9 PDD).

Radiochemistry. Using the technique of Lee et al., ${ }^{13}$ (R, R) ${ }^{123} \mathrm{I}$ $\mathrm{QNB}$ radiosynthesis was conducted, the specifics of which are described elsewhere. ${ }^{14}$

Acquisition. Participants were scanned with a triple-head gamma camera (Picker 3000XP; Philips, Best, the Netherlands) 5 hours postinjection of $(\mathrm{R}, \mathrm{R}){ }^{123} \mathrm{I}$-QNB using a previously reported imaging protocol. ${ }^{8}$ Within 4 weeks of the (R, R) ${ }^{123} \mathrm{I}$ QNB scan, individuals underwent ${ }^{99 \mathrm{~m}} \mathrm{Tc}$-exametazime regional cerebral blood flow (rCBF) SPECT imaging in accordance with a past scanning procedure. ${ }^{8}$
Spatial preprocessing. All SPECT scans were registered to match, where applicable, a ${ }^{123} \mathrm{I}-\mathrm{QNB}$ or ${ }^{99 \mathrm{~m}} \mathrm{~T}$ c-exametazime SPECT template in standard stereotactic Montreal Neurological Institute space using linear image registration software (http://fsl.fmrib.ox.ac.uk/fsl/fslwiki/ flirt/). Generation of specific template images have been described. ${ }^{14,15}$ The spatially transformed images were then smoothed with a $10-\mathrm{mm}$ full width at half maximum 3D Gaussian filter.

Multivariate spatial covariance analysis. Principal component (PC) analysis was applied on a voxel basis to all processed ${ }^{123} \mathrm{I}-\mathrm{QNB}$ SPECT images using covariance analysis software (http://www.nitrc.org/projects/gcva_pca/), ${ }^{16}$ producing a series of PC images. For each PC image, voxels had either positive or negative weights that represent the sign and strength of covariance between voxels. In this study, voxels with positive and negative weights were viewed as concurrently preserved/increased and decreased M1/M4 binding, respectively. The extent to which an individual expressed the PC image was by way of a subject scaling factor (SSF) for that PC, calculated by superimposing the PC image onto an individual's processed QNB scan by computation of a dot product, which involves image multiplication on a voxel basis followed by summation of the products generating a score. Higher SSF scores for an individual for that PC image represents greater increased binding in voxels with positive weights and greater concurrent decreased binding in voxels with negative weights. To identify the QNB spatial covariance pattern (SCP) that distinguished PDD from controls, each individual SSF was entered into a linear regression model as explanatory variables with group as the dependent parameter. Akaike information criteria (AICs) determined how many PCs should be included to reach optimal bias-variance tradeoff. ${ }^{17}$ The set of PCs yielding the lowest AIC value was used to derive the $\mathrm{SCP}_{\mathrm{QNB}}$. The degree to which each participant expressed the $\mathrm{SCP}_{\mathrm{QNB}}$ was by the $\mathrm{SSF}_{\mathrm{QNB}}$.

The same approach was applied to the ${ }^{99 \mathrm{~m}} \mathrm{~T} \mathrm{c}$-exametazime SPECT images. Therefore, positive and negative weights were interpreted as concurrent increased and decreased rCBF, respectively. The analysis produced the $\mathrm{SCP}_{\mathrm{rCBF}}$ that best separated PDD from controls, while each participant expressed the $\mathrm{SCP}_{\mathrm{rCBF}}$ by his or her $\mathrm{SSF}_{\mathrm{rCBF}}$.

Following their ${ }^{123} \mathrm{I}-\mathrm{QNB}$ scan, the majority of patients $(\mathrm{n}=$ 18) were then treated with the ChEI donepezil titrated up to the standard daily clinical dose of $10 \mathrm{mg}$. After a period of 12 weeks, patients underwent repeated MMSE assessments. We derived a ChEI-naive M1/M4 SCP that correlated with $\triangle \mathrm{MMSE}_{\text {rel_b}}$, which described the percentage change in MMSE relative to baseline. This involved conducting a separate analysis, generating a series of PCs expressed by each participant by the SSFs, which in turn were introduced into a regression model as predictor variables with $\triangle \mathrm{MMSE}_{\text {rel_b }}$ as the response parameter. The resulting linear combination with the smallest AIC value generated the $\mathrm{SCP}_{\triangle \mathrm{MMSE}}$ $\left(R^{2}=0.34, p=0.005\right)$, where each individual expressed the pattern by the $S_{S F} F_{\triangle M M S E}$.

Stability and reliability of the SCPs were assessed by bootstrap resampling (1,000 iterations) to identify areas that contributed to the patterns with high confidence. This transforms the voxel weights of each SCP into $Z$ maps, computed as the ratio of voxel weight and bootstrap SD. The $Z$-statistic follows roughly a standard normal distribution where a one-tailed $p \leq 0.05$ infers a threshold of $|Z| \geq 1.64 .^{18}$

Statistical analyses. Continuous variables were tested for normality using visual inspection of histograms and Shapiro-Wilk test. Demographic, clinical, and imaging measures were assessed, where applicable, using parametric (analysis of variance) and nonparametric $\chi^{2}$ tests. Correlations were performed using Pearson $r$ coefficients. 


\begin{tabular}{|llll|}
\hline Table 1 & Participant characteristics & & \\
& Controls & PDD & Statistic, p value \\
No. & 24 & 25 & \\
M:F & $15: 9$ & $17: 8$ & $\chi^{2}=0.2,0.7$ \\
Age, y & $74.1 \pm 5.1$ & $72.0 \pm 5.0$ & $F_{1,47}=2.0,0.2$ \\
MMSE & $28.3 \pm 1.5$ & $18.8 \pm 4.9$ & $F_{1,47}=82.3,<0.001$ \\
CAMCOG & $95.0 \pm 3.9$ & $63.0 \pm 14.2$ & $F_{1,47}=113.8,<0.001$ \\
CAMCOG $_{\text {memory }}$ & $22.1 \pm 1.9$ & $16.1 \pm 4.7$ & $F_{1,47}=32.6,<0.001$ \\
CAMCOG $_{\text {exec }}$ & $20.8 \pm 4.2$ & $8.5 \pm 3.1$ & $F_{1,47}=135.2,<0.001$ \\
NPI $_{\text {NPI }}$ & $1.3 \pm 2.3$ & $19.7 \pm 17.8$ & $U=73.0,0.002$ \\
UPDRS III & NA & $3.5 \pm 2.5$ & \\
\hline
\end{tabular}

Abbreviations: $\mathrm{CAMCOG}=$ Cambridge Cognitive Examination; $\mathrm{CAMCOG}_{\mathrm{exec}}=$ Cambridge Cognitive Examination executive function subscale; $\mathrm{CAMCOG}_{\text {memory }}=$ Cambridge Cognitive Examination memory subscale; MMSE = Mini-Mental State Examination; NA = not applicable; $\mathrm{NPI}_{\text {hall }}=$ Neuropsychiatric Inventory hallucinations subscale; $\mathrm{PDD}=$ Parkinson disease dementia; UPDRS = Unified Parkinson's Disease Rating Scale.

Values denote mean \pm 1 SD.
RESULTS Demographics and clinical characteristics. Table 1 shows demographic and clinical characteristics of the study sample. Groups were similar in age and sex, while as expected, all other variables differed $(p<0.001)$.

Spatial covariance analysis. The $\mathrm{SCP}_{\mathrm{QNB}}$ that distinguished PDD from controls is shown in figure 1, A and $\mathrm{B} . \mathrm{SSF}_{\mathrm{QNB}}$ scores were higher in PDD than controls (mean $\pm \mathrm{SD}$; controls $=1.5 \pm 2.5, \mathrm{PDD}=$ $6.2 \pm 3.3, F_{1,47}=31.9, p<0.001$; figure 1C). The pattern was mainly characterized by concomitant decreases in M1/M4 binding (blue regions) in basal forebrain, temporal, striatal, insula, and anterior cingulate together with concomitant preserved or increases (red regions) in frontal and parieto-occipital areas. Table e-1 on the Neurology ${ }^{\circledR}$ Web site at Neurology.org presents detailed description of specific regions contributing to the M1/M4 disease-related pattern.

The associated $\mathrm{SCP}_{\mathrm{rCBF}}$ that differentiated PDD from controls is illustrated in figure 2, A and B, where $\mathrm{SSF}_{\mathrm{rCBF}}$ scores differed between groups (controls $=$ $0.4 \pm 0.9, \mathrm{PDD}=6.2 \pm 1.9, F_{1,47}=177.5, p<$ 0.001 ; figure $2 \mathrm{C}$ ). The pattern mainly comprised relative decreased $\mathrm{rCBF}$ (blue) in temporoparietal and
Statistical tests were interpreted as significant if $p \leq 0.05$. Data analysis used the Statistical Package for Social Sciences (Chicago, IL) software (SPSS version 22.0; http://www-01.ibm.com/software/analytics/spss/ products/statistics/).

Figure 1 Muscarinic M1/M4 spatial covariance pattern in Parkinson disease dementia (PDD)

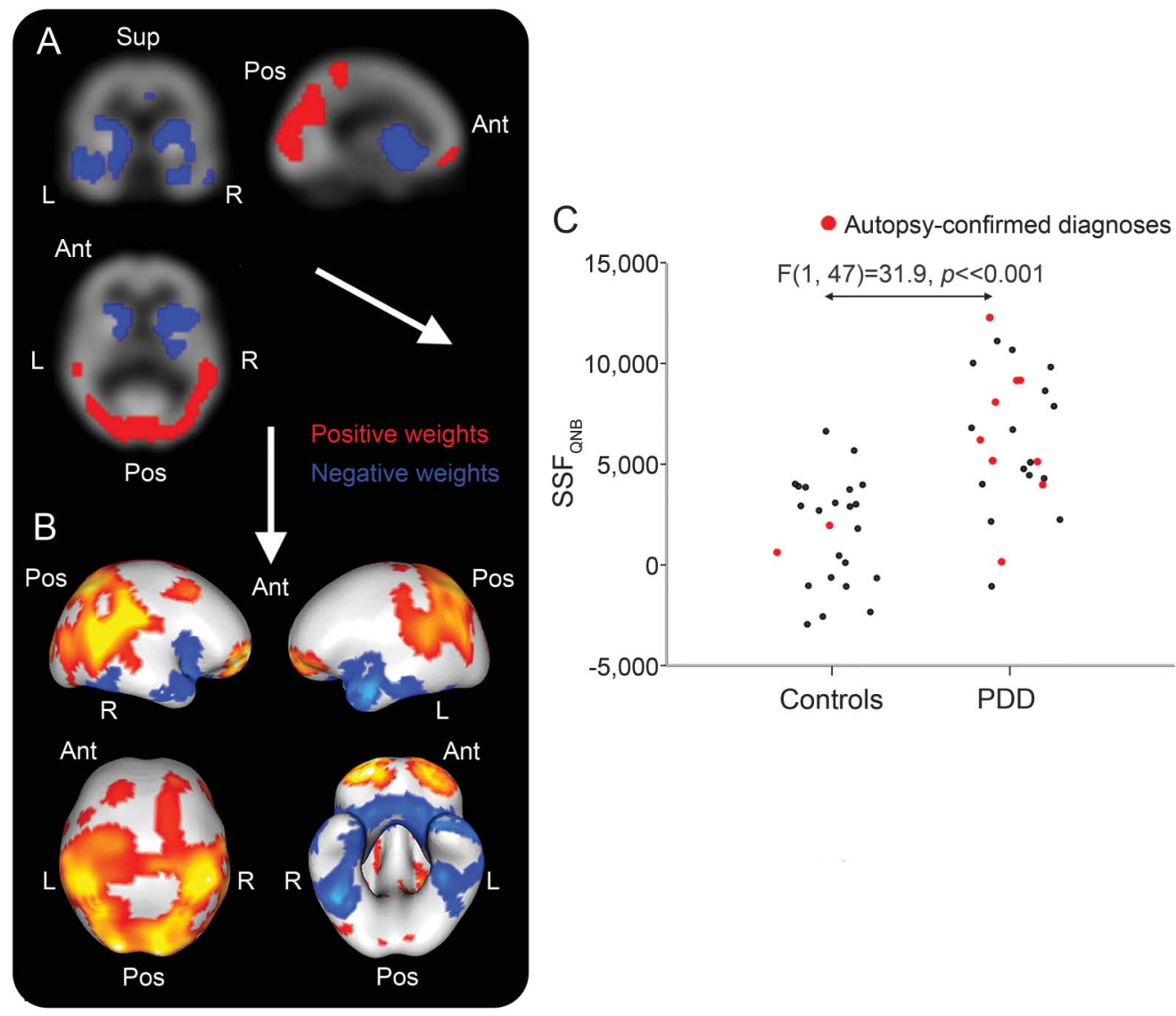

Disease-related M1/M4 spatial covariance pattern in PDD projected onto orthogonal (A) and rendered (B) displays of the QNB template. Distribution of subject scaling factor ( $\mathrm{SSF}_{\mathrm{QNB}}$ ) scores across groups $(\mathrm{C})$. Ant = anterior; Pos = posterior; Sup = superior. 


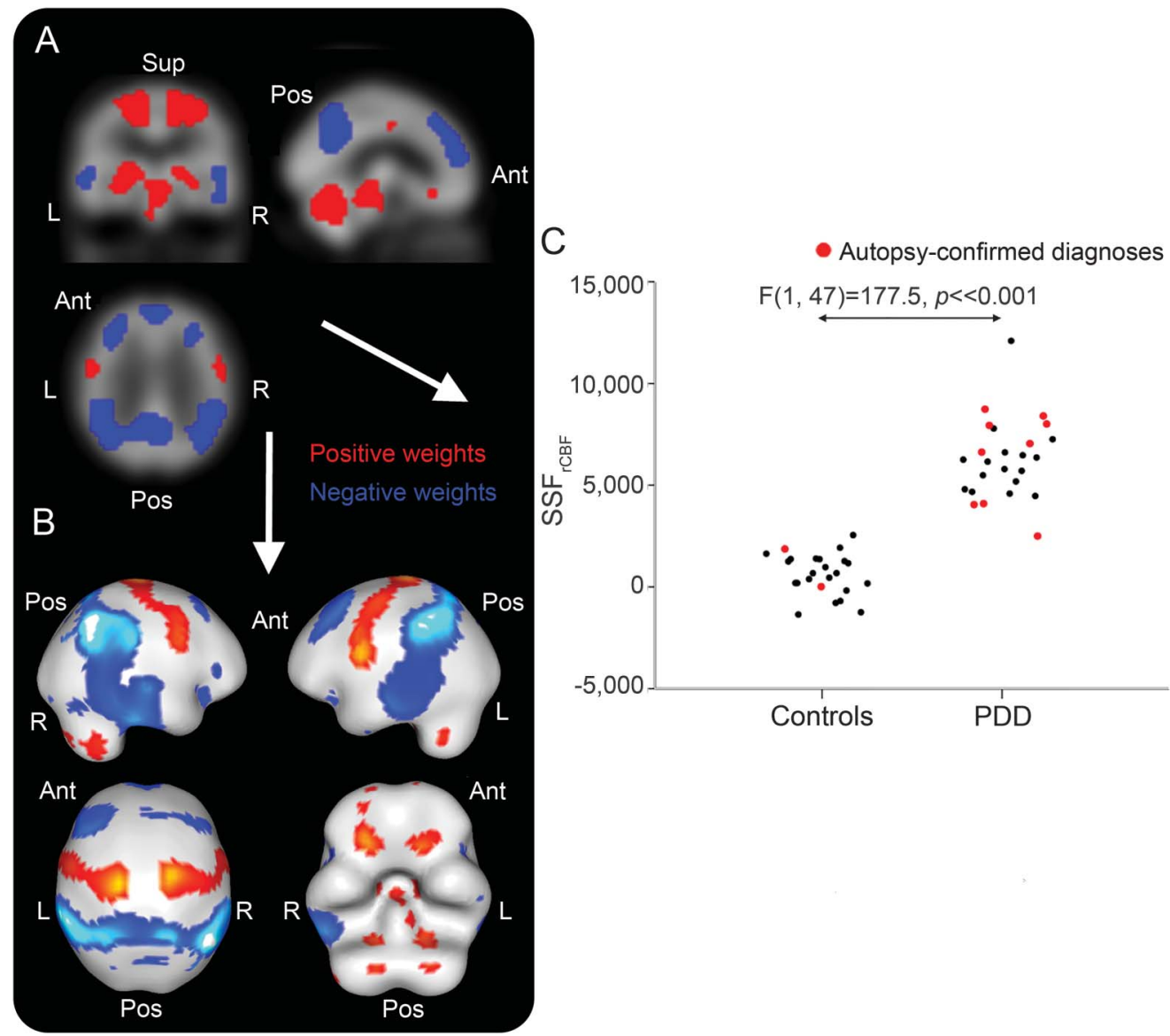

Disease-related rCBF spatial covariance pattern in PDD projected onto orthogonal (A) and rendered (B) displays of the rCBF template. Distribution of subject scaling factor $\left(\mathrm{SSF}_{\mathrm{rCBF}}\right)$ scores across groups (C). Ant $=$ anterior; Pos $=$ posterior; Sup = superior.

prefrontal areas with relative increases (red) in cerebellum, brainstem, striatothalamic, and motor regions. Detailed description of specific regions participating in the $\mathrm{rCBF}$ disease-related pattern is provided (table e-2).

Relationships between SCP expressions and age, MMSE, CAMCOG, CAMCOG memory, CAMCO$G_{\text {exec }}$, total NPI, NPI hallucinations subscale, and Unified Parkinson's Disease Rating Scale III were investigated in PDD. No correlations were found between $\operatorname{SSF}_{\mathrm{QNB}}$ and these measures $(|r| \leq 0.23$, $p \geq 0.14)$. For the rCBF pattern expression, total NPI correlated with $\operatorname{SSF}_{\mathrm{rCBF}}(\rho=0.62, p=$ 0.006 ), which was not observed for the other variables $(|r| \leq 0.28, p \geq 0.09)$. An exploratory examination of NPI subscores did not yield any specific relationships with SCP expressions.

Summary data for the donepezil-treated group are shown (table 2). During the observation period, differences in MMSE were identified between baseline and 12 -week scores $(p<0.001)$. The resultant $\mathrm{SCP}_{\triangle \mathrm{MMSE}}$ is presented in figure $3, \mathrm{~A}$ and $\mathrm{B}$, while figure $3 \mathrm{C}$ depicts $\mathrm{SSF}_{\triangle \mathrm{MMSE}}$ plotted as a function of $\triangle \mathrm{MMSE}_{\text {rel_b }}$. The pattern consists of concurrent decreases in M1/M4 binding (blue) in fusiform, anterior cingulate, lingual gyrus, and precentral areas with concurrent preserved or increases (red) in pre/medial/ orbitofrontal, parietal, and posterior cingulate regions.

\begin{tabular}{|ll|}
\hline Table 2 & $\begin{array}{l}\text { Summary data of patients with PDD } \\
\text { treated with donepezil }\end{array}$ \\
& PDD donepezil $\quad$ Statistic, $p$ value \\
\hline No. & 18 \\
M:F & $11: 7$ \\
Age & $71.6 \pm 4.6$ \\
MMSE $_{\mathrm{b}}$ & $18.1 \pm 4.3$ \\
MMSE $_{12 w}$ & $22.4 \pm 4.7$ \\
$\mid$ MMSE $_{12 w}-$ MMSE $_{\mathrm{b} \mid} \mid$ & $4.3 \pm 3.8$ \\
MMMSE $_{\text {rel_b, } \%}$ & $26.8 \pm 24.6$ \\
\hline
\end{tabular}

Abbreviations: $12 \mathrm{w}=$ at 12 weeks; $\mathrm{b}=$ at baseline; MMSE $=$ Mini-Mental State Examination; PDD = Parkinson disease dementia.

Values denote mean \pm 1 SD.

$\Delta \mathrm{MMSE}_{\text {rel } \mathrm{b}}(\%)=\left\{\left(\mathrm{MMSE}_{12 \mathrm{w}}-\mathrm{MMSE}_{\mathrm{b}}\right) / \mathrm{MMSE}_{\mathrm{b}}\right\} \times 100 \%$. 
Figure $3 \quad$ M1/M4 spatial covariance pattern (SCP) $\Delta$ Mini-Mental State Examination (MMSE) in Parkinson disease dementia (PDD) $(n=18)$

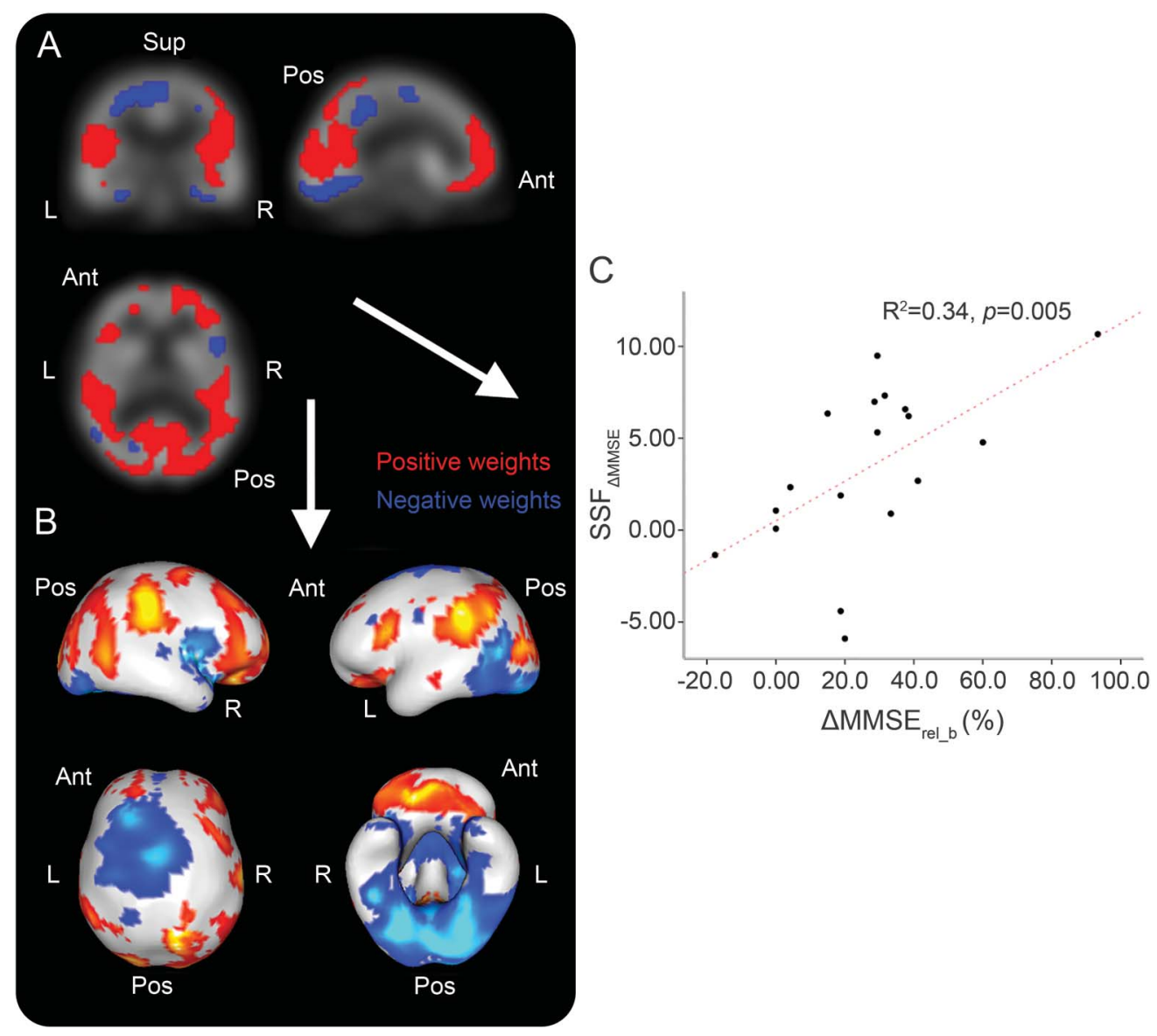

(A-C) M1/M4 SCP in PDD $(n=18)$ that correlated with $\triangle M_{M M S E}$ rel_b.

Details of specific regions participating in the pattern are supplied (table e-3).

DISCUSSION We undertook a multivariate network perspective of $(R, R){ }^{123} I-Q N B$ SPECT, a M1/M4 receptor ligand in ChEI-naive patients with PDD. We derived a disease-related M1/M4 pattern of spatial covariance that appears largely distinct from rCBF, which implies the presence of several dysfunctional cholinergic networks in PDD. We also identified a clear M1/M4 covariance pattern that was associated with an improvement in MMSE; this network had distinctive spatial elements suggesting certain cortical regions and their associated cholinergic innervation may have a more preeminent role in cognitive amelioration by cholinergic treatments. Relevant to the present study, this spatial covariance technique has extensively and successfully been utilized in perfusion SPECT and glucose metabolism PET data for the investigation of disease progression and symptomatology in PD. ${ }^{19-22}$

We derived a voxel cholinergic SCP from ${ }^{123}$ I-QNB images that differentiated PDD from controls. The disease-related pattern comprised decreased and preserved/increased M1/M4 uptake in a number of concomitant brain regions or networks. The covariant negative-weighted pattern mainly converged on limbic/paralimbic regions. Notably, this cholinergic receptor network mapped onto previously described resting-state networks, including anterior insula and the anterior cingulate, key nodes of the salience network (SN), which is important for initiation of cognitive control and switching between networks to aid access to working memory and attention resources. ${ }^{23,24}$ Networks involving the insula have also been shown to play a role in episodic memory, ${ }^{25}$ while hippocampus, parahippocampus, and amygdala are known to be involved in memory storage and retrieval. ${ }^{26}$ As such, this pattern would align with a cognitive network deficit implicating the basal forebrain and these structures, i.e., a cholinergic limbic-paralimbic/SN dysfunction. The disease-related pattern also encompassed regions implicated in dorsal (occipital $\rightarrow$ parietal) and ventral (occipital $\rightarrow$ tempo$\mathrm{ral} \rightarrow$ limbic) visual streams, ${ }^{27}$ providing indirect evidence for the role of distinct cholinergic networks in visual function in PDD, which would be in keeping with known visuoperceptual deficits and predisposition 
to visual hallucinations, symptoms that both show good response to cholinesterase inhibitors. ${ }^{28,29}$

The associated rCBF pattern largely comprised relative decreases in temporoparietal and prefrontal areas along with relative increases in cerebellum, brainstem, striatothalamic, and motor regions that implicate a number of functional networks in PDD. Regions that were concomitantly reduced appear to involve hubs of the frontoparietal attention (inferior parietal, dorsolateral prefrontal cortex $)^{30}$ and default mode networks (DMNs) (medial prefrontal, posterior cingulate, ventral precuneus, inferior parietal), ${ }^{31,32}$ which is of interest since, respectively, attention deficits are one of the most disabling cognitive symptoms in $\mathrm{PDD},{ }^{33}$ while network theories have strongly implicated the DMN in contributing to cognitive decline. ${ }^{34}$ Our previous studies revealed modulation of the frontoparietal network in PDD that was similar to patients with dementia with Lewy bodies (DLB), ${ }^{35}$ while also demonstrating, albeit in DLB, its relationship with severity and frequency of cognitive fluctuations. ${ }^{36}$ Other investigations have reported decreases in $\mathrm{DMN}$ connectivity in $\mathrm{PDD}^{37}$ and its association with cognitive dysfunction in PD. ${ }^{38}$ These and our rCBF findings appear to provide further evidence that implicate the DMN and frontoparietal networks in the pathogenesis of symptoms in PDD, in particular cognitive. Moreover, perhaps not unexpectedly, the rCBF pattern seemed to represent an extended topography of the PD-related motor and cognitive patterns, which have been previously reported from ${ }^{18} \mathrm{~F}-\mathrm{FDG}$ PET studies using similar network approaches, ${ }^{21,39}$ thus indirectly validating the analytic methodology used in the present study.

We failed to detect any correlations between the M1/M4 pattern expressions and neuropsychological and neuropsychiatric measures in PDD. For rCBF pattern expression, only total NPI score was found to correlate. Thus, patients with more global severe neuropsychiatric symptoms, a marker of greater disease severity, were more likely to express the perfusion SCP characteristic of PDD. The lack of correlations may be explained by either the notion that each spatial covariance pattern is likely to characterize a number of overlapping and convergent brain networks and thus fails to project on specific cognitive and clinical parameters or that patterns derived from combined (control-dementia) cohorts are less sensitive. Isolating key networks from these patterns could increase sensitivity, but this is methodologically challenging.

We found a clear M1/M4 covariance pattern that correlated with a change in MMSE that could indicate a positive treatment response. This pattern showed relative decreases in fusiform, striatum, anterior cingulate, lingual gyrus, and precentral areas with relative preservation or increase in $\mathrm{pre} / \mathrm{medial} /$ orbitofrontal, parietal, and posterior cingulate regions. From a network perspective, there was covariant preservation/ upregulation in regions overlapping key nodes of the DMN and frontoparietal networks that could imply that a relative cholinergic maintenance of these networks is prerequisite for ChEI treatment response in PDD, and more generally may point toward the potential relevance of these networks and their cholinergic innervation and its associated cognitive symptoms. Notably, a recent study showed that cholinergic and serotonergic antagonists can impair DMN-like network in mice similarly, suggesting that both neurotransmitter systems are involved in maintaining the integrity of the DMN-like networks. ${ }^{40}$ Hence, this pattern appears to provide some evidence that supports the cholinergic DMN maintenance hypothesis, and its potential significance as a predictor of positive treatment response in PDD and perhaps in other neurodegenerative disorders.

Modest sample sizes and uncertainty regarding which receptor subtype is affected (that is, M1 vs M4) are limitations of the study. Another limitation was the use of MMSE rather than Montreal Cognitive Assessment to assess cognitive function in these patients, reflecting the fact that our data were collected before the widespread use of the latter scale. Replication of this study with neuropsychological assessments that align more with the cognitive deficit profile of PDD may provide a more nuanced cholinergic response network pattern. Strengths were scanning and clinically assessing patients with PDD free from cholinergic medications with perfusion and muscarinic SPECT images available for all participants. We also had, in a sizeable minority, autopsy confirmation of diagnoses.

Our findings imply several dysfunctional cholinergic and perfusion networks in PDD. The relevance of these networks may be important in terms of their contribution to cognitive and, in particular, attentional deficits of this condition. The use of ChEIs could improve such deficits, but there is marked heterogeneity in response to these agents and it is not possible to reliably predict on clinical grounds who might respond to these drugs. Although tentative, we observed a SCP that suggests that those with cholinergic maintenance of DMN and frontoparietal networks could experience cognitive improvement with ChEI treatment. These findings provide further neurobiological insights into therapies targeted at improving cholinergic neurotransmission and treatment outcomes in PDD.

\section{AUTHOR CONTRIBUTIONS}

Dr. Colloby: co-designed the study, conducted all image and data analyses, and wrote the manuscript. Professor McKeith: reviewed the manuscript and secured project funding. Professor Burn: reviewed the manuscript and secured project funding. Professor Wyper: reviewed the manuscript and secured project funding. Professor O'Brien: reviewed 
the manuscript and secured project funding. Dr. Taylor: co-designed the study and cowrote the manuscript.

\section{STUDY FUNDING}

Supported by Medical Research Council UK (grant G9817682), the National Institute for Health Research (NIHR), Research for Public Benefit, Wellcome Trust (WT088441MA Fellowship funding J.-P.T.); NIHR Dementia Biomedical Research Unit at Cambridge University Hospitals, NHS Foundation Trust, the University of Cambridge; and The NIHR Newcastle Biomedical Research Centre in Ageing and Chronic Disease, Biomedical Research Unit in Lewy Body Dementia based at Newcastle upon Tyne Hospitals, NHS Foundation Trust and Newcastle University.

\section{DISCLOSURE}

S. Colloby reports no disclosures relevant to the manuscript. I. McKeith has been a consultant for GE Healthcare, Bayer Health care, and Nutricia. D. Burn has received an honorarium from Acadia. D. Wyper reports no disclosures relevant to the manuscript. J. O'Brien has been a consultant for GE Healthcare, Lilly, Bayer Healthcare, TauRx, and Nutricia and has received honoraria for talks from GE Healthcare, Lilly, and Novartis. J. Taylor has been a consultant of Lundbeck and received honoraria for talks from GE Healthcare and Flynn Pharmaceuticals. Go to Neurology.org for full disclosures.

Received October 28, 2015. Accepted in final form March 30, 2016.

\section{REFERENCES}

1. Buter TC, van den Hout A, Matthews FE, Larsen JP, Brayne C, Aarsland D. Dementia and survival in Parkinson disease: a 12-year population study. Neurology 2008; 70:1017-1022.

2. Pigott K, Rick J, Xie SX, et al. Longitudinal study of normal cognition in Parkinson disease. Neurology 2015; 85:1276-1282.

3. Aarsland D, Litvan I, Salmon D, Galasko D, WentzelLarsen T, Larsen JP. Performance on the dementia rating scale in Parkinson's disease with dementia and dementia with Lewy bodies: comparison with progressive supranuclear palsy and Alzheimer's disease. J Neurol Neurosurg Psychiatry 2003;74:1215-1220.

4. Tiraboschi P, Hansen LA, Alford M, et al. Cholinergic dysfunction in diseases with Lewy bodies. Neurology 2000;54:407-411.

5. van Laar T, De Deyn PP, Aarsland D, Barone P, Galvin JE. Effects of cholinesterase inhibitors in Parkinson's disease dementia: a review of clinical data. CNS Neurosci Ther 2011;17:428-441.

6. Pievani M, de Haan W, Wu T, Seeley WW, Frisoni GB. Functional network disruption in the degenerative dementias. Lancet Neurol 2011;10:829-843.

7. Gratwicke J, Jahanshahi M, Foltynie T. Parkinson's disease dementia: a neural networks perspective. Brain 2015; 138:1454-1476.

8. Colloby SJ, Pakrasi S, Firbank MJ, et al. In vivo SPECT imaging of muscarinic acetylcholine receptors using $(R, R)$ 123I-QNB in dementia with Lewy bodies and Parkinson's disease dementia. Neuroimage 2006;33:423-429.

9. Folstein MF, Folstein SE, McHugh PR. "Mini-mental state": a practical method for grading the cognitive state of patients for the clinician. J Psychiatr Res 1975;12:189-198.

10. Cummings JL, Mega M, Gray K, Rosenberg-Thompson S, Carusi DA, Gornbein J. The neuropsychiatric inventory: comprehensive assessment of psychopathology in dementia. Neurology 1994;44:2308-2314.

11. Roth M, Tym E, Mountjoy CQ, et al. CAMDEX: a standardised instrument for the diagnosis of mental disorder in the elderly with special reference to the early detection of dementia. Br J Psychiatry 1986;149:698-709.

12. Emre M, Aarsland D, Brown R, et al. Clinical diagnostic criteria for dementia associated with Parkinson's disease. Mov Disord 2007;22:1689-1707; quiz 1837.

13. Lee KS, He XS, Jones DW, et al. An improved method for rapid and efficient radioiodination of iodine-123-IQNB. J Nucl Med 1996;37:2021-2024.

14. Pakrasi S, Colloby SJ, Firbank MJ, et al. Muscarinic acetylcholine receptor status in Alzheimer's disease assessed using (R, R) 123I-QNB SPECT. J Neurol 2007;254:907-913.

15. Colloby SJ, Firbank MJ, Pakrasi S, et al. A comparison of ${ }^{99 \mathrm{~m}}$ Tc-exametazime and ${ }^{123}$ I-FP-CIT SPECT imaging in the differential diagnosis of Alzheimer's disease and dementia with Lewy bodies. Int Psychogeriatr 2008;20:1-17.

16. Habeck C, Krakauer JW, Ghez C, et al. A new approach to spatial covariance modeling of functional brain imaging data: ordinal trend analysis. Neural Comput 2005;17:1602-1645.

17. Burnham KP, Anderson DR. Model Selection and Multimodel Inference. New York: Springer Verlag; 2002.

18. Habeck C, Stern Y. Multivariate data analysis for neuroimaging data: overview and application to Alzheimer's disease. Cell Biochem Biophys 2010;58:53-67.

19. Eckert T, Van Laere K, Tang C, et al. Quantification of Parkinson's disease-related network expression with ECD SPECT. Eur J Nucl Med Mol Imaging 2007;34:496-501.

20. Fukuda M, Edwards C, Eidelberg D. Functional brain networks in Parkinson's disease. Parkinsonism Relat Disord 2001;8:91-94.

21. Huang C, Tang C, Feigin A, et al. Changes in network activity with the progression of Parkinson's disease. Brain 2007;130:1834-1846.

22. Niethammer M, Tang CC, Ma Y, et al. Parkinson's disease cognitive network correlates with caudate dopamine. Neuroimage 2013;78:204-209.

23. Menon V, Uddin LQ. Saliency, switching, attention and control: a network model of insula function. Brain Struct Funct 2010;214:655-667.

24. Seeley WW, Menon V, Schatzberg AF, et al. Dissociable intrinsic connectivity networks for salience processing and executive control. J Neurosci 2007;27:2349-2356.

25. Xie C, Bai F, Yu H, et al. Abnormal insula functional network is associated with episodic memory decline in amnestic mild cognitive impairment. Neuroimage 2012;63:320-327.

26. Lech RK, Suchan B. The medial temporal lobe: memory and beyond. Behav Brain Res 2013;254:45-49.

27. Foley RT, Whitwell RL, Goodale MA. The two-visualsystems hypothesis and the perspectival features of visual experience. Conscious Cogn 2015;35:225-233.

28. Burn D, Emre M, McKeith I, et al. Effects of rivastigmine in patients with and without visual hallucinations in dementia associated with Parkinson's disease. Mov Disord 2006;21:1899-1907.

29. McKeith IG, Wesnes KA, Perry E, Ferrara R. Hallucinations predict attentional improvements with rivastigmine in dementia with Lewy bodies. Dement Geriatr Cogn Disord 2004;18:94-100.

30. Markett S, Reuter M, Montag C, et al. Assessing the function of the fronto-parietal attention network: insights from resting-state fMRI and the attentional network test. Hum Brain Mapp 2014;35:1700-1709.

31. Buckner RL. The brain's default network: origins and implications for the study of psychosis. Dialogues Clin Neurosci 2013;15:351-358. 
32. van den Heuvel MP, Hulshoff Pol HE. Exploring the brain network: a review on resting-state fMRI functional connectivity. Eur Neuropsychopharmacol 2010; 20:519-534.

33. Bronnick K, Ehrt U, Emre M, et al. Attentional deficits affect activities of daily living in dementia-associated with Parkinson's disease. J Neurol Neurosurg Psychiatry 2006; 77:1136-1142.

34. Seeley WW, Crawford RK, Zhou J, Miller BL, Greicius MD. Neurodegenerative diseases target large-scale human brain networks. Neuron 2009;62:42-52.

35. Peraza LR, Colloby SJ, Firbank MJ, et al. Resting state in Parkinson's disease dementia and dementia with Lewy bodies: commonalities and differences. Int J Geriatr Psychiatry 2015;30:1135-1146.

36. Peraza LR, Kaiser M, Firbank M, et al. fMRI resting state networks and their association with cognitive fluctuations in dementia with Lewy bodies. Neuroimage Clin 2014;4: $558-565$.

37. Rektorova I, Krajcovicova L, Marecek R, Mikl M. Default mode network and extrastriate visual resting state network in patients with Parkinson's disease dementia. Neurodegener Dis 2012;10:232-237.

38. Spetsieris PG, Ko JH, Tang CC, et al. Metabolic restingstate brain networks in health and disease. Proc Natl Acad Sci USA 2015;112:2563-2568.

39. Huang C, Mattis $P$, Tang C, Perrine K, Carbon M, Eidelberg D. Metabolic brain networks associated with cognitive function in Parkinson's disease. Neuroimage 2007;34:714-723.

40. Shah D, Blockx I, Keliris GA, et al. Cholinergic and serotonergic modulations differentially affect large-scale functional networks in the mouse brain. Brain Struct Funct Epub 2015 Jul 21.

\section{Share Your Artistic Expressions in Neurology 'Visions'}

AAN members are urged to submit medically or scientifically related artistic images, such as photographs, photomicrographs, and paintings, to the "Visions" section of Neurology ${ }^{\circledR}$. These images are creative in nature, rather than the medically instructive images published in the NeuroImages section. The image or series of up to six images may be black and white or color and must fit into one published journal page. Accompanying description should be 100 words or less; the title should be a maximum of 96 characters including spaces and punctuation.

Learn more at www.aan.com/view/Visions, or upload a Visions submission at submit.neurology.org.

\section{Visit the Neurology ${ }^{\circledR}$ Web Site at Neurology.org}

- Enhanced navigation format

- Increased search capability

- Highlighted articles

- Detailed podcast descriptions

- RSS Feeds of current issue and podcasts

- Personal folders for articles and searches

- Mobile device download link

- AAN Web page links

- Links to Neurology Now ${ }^{\circledR}$, Neurology Today ${ }^{\circledR}$, and Continuum ${ }^{\circledR}$

- Resident \& Fellow subsite

(1) Find Neurology ${ }^{\circledR}$ on Facebook: http://tinyurl.com/neurologyfan

twitter Follow Neurology ${ }^{\circledR}$ on Twitter: https://twitter.com/GreenJournal 


\section{Neurology}

\section{Cholinergic and perfusion brain networks in Parkinson disease dementia}

Sean J. Colloby, Ian G. McKeith, David J. Burn, et al.

Neurology 2016;87;178-185 Published Online before print June 15, 2016

DOI 10.1212/WNL.0000000000002839

This information is current as of June 15, 2016

\begin{tabular}{|c|c|}
\hline $\begin{array}{l}\text { Updated Information \& } \\
\text { Services }\end{array}$ & $\begin{array}{l}\text { including high resolution figures, can be found at: } \\
\text { http://n.neurology.org/content/87/2/178.full }\end{array}$ \\
\hline Supplementary Material & $\begin{array}{l}\text { Supplementary material can be found at: } \\
\text { http://n.neurology.org/content/suppl/2016/06/15/WNL. } 0000000000002 \\
\text { 839.DC1 }\end{array}$ \\
\hline References & $\begin{array}{l}\text { This article cites } 38 \text { articles, } 10 \text { of which you can access for free at: } \\
\text { http://n.neurology.org/content/ } 87 / 2 / 178 \text {.full\#ref-list- } 1\end{array}$ \\
\hline Subspecialty Collections & $\begin{array}{l}\text { This article, along with others on similar topics, appears in the } \\
\text { following collection(s): } \\
\text { Parkinson's disease with dementia } \\
\text { http://n.neurology.org/cgi/collection/parkinsons_disease_with_dementi } \\
\text { a } \\
\text { SPECT } \\
\text { http://n.neurology.org/cgi/collection/spect }\end{array}$ \\
\hline Permissions \& Licensing & $\begin{array}{l}\text { Information about reproducing this article in parts (figures,tables) or in } \\
\text { its entirety can be found online at: } \\
\text { http://www.neurology.org/about/about_the_journal\#permissions }\end{array}$ \\
\hline Reprints & $\begin{array}{l}\text { Information about ordering reprints can be found online: } \\
\text { http://n.neurology.org/subscribers/advertise }\end{array}$ \\
\hline
\end{tabular}

Neurology ${ }^{\circledR}$ is the official journal of the American Academy of Neurology. Published continuously since 1951, it is now a weekly with 48 issues per year. Copyright (O 2016 American Academy of Neurology. All rights reserved. Print ISSN: 0028-3878. Online ISSN: 1526-632X.

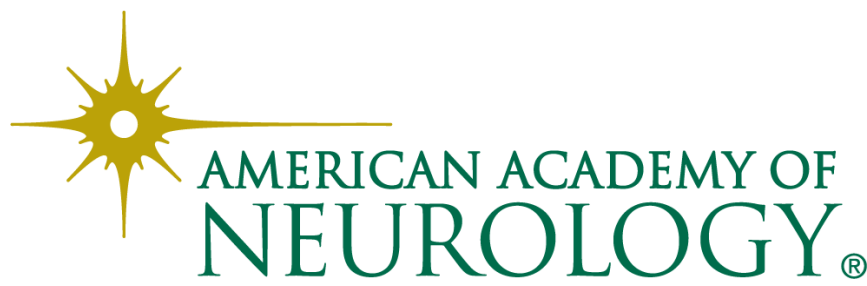

